\title{
Controle e disseminação
}

Auctoritas e faits divers no início da imprensa

Rafael Viegas*

RESUMO: O artigo mostra como o estudo dos faits divers e seu contexto editorial no final do Renascimento ajudam a entender de que modo a auctoritas pré-moderna, sempre pautada no respeito aos clássicos greco-romanos, cria, a partir de um embate com as epistemes populares, um sistema de legitimação diferente da estrutura hierárquica medieval dos saberes.

PALAVRAS-CHAVE: auctoritas; fait-divers; imprensa.

\section{Control and dissemination}

\section{Auctoritas and faits divers at the beginning of the press}

\begin{abstract}
This paper shows how the study of faits divers and their editorial context at the end of the Renaissance helps to understand how the pre-modern auctoritas, always based on Greco-Roman classics, creates, through a discussion with popular epistemes, a legitimation system that is different from the medieval hierarchical knowledge structure.
\end{abstract}

KEYWORDS: auctoritas, faits divers, press.

\section{Contrôle et diffusion}

\section{Auctoritas et faits divers aux débuts de la presse}

RESUMÉ : Cet article montre que l'étude des faits divers du XVIe-XVIIe siècles et de leur contexte éditorial permet de comprendre comment l'auctoritas prémoderne, toujours basée sur les classiques gréco-romains, a créé, à partir d'un choc avec les épistèmes populaires, un modèle qui diffère de la structuration médiévale hiérarchique de la connaissance.

MOTS-CLÉS : auctoritas; fait divers; presse.

* Rafael Viegas é Doutor em Saúde Coletiva (IMS-UERJ) e em Letras (FL-UFRJ), pós-doutorando em Filosofia (PFIUFF/PNPD Capes) e pesquisador associado no IEL-Unicamp e no CEREdI (Université de Rouen). 
O que é um fait divers? A definição fenomenologicamente mais simples e direta seria: toda notícia extraordinária veiculada por um jornal impresso que flutua sem muito lugar dentro da diagramação de seus cadernos clássicos. A definição mais conhecida de fait divers, porém, é a de Barthes, e esta implica, para além dessa relação diagramática (tipográfica e topográfica), uma relação crítica e narrativa.

O assassinato político é sempre, por definição, uma informação parcial; o fait divers, pelo contrário, é uma informação total, ou mais exatamente, imanente; ele contém em si todo seu saber: não é preciso conhecer nada do mundo para consumir um fait divers; ele não remete formalmente a nada além de si próprio; evidentemente, seu conteúdo não é estranho ao mundo: desastres, assassinatos, raptos, agressões, acidentes, roubos, esquisitices, tudo isso remete ao homem, à sua história, à sua alienação, a seus fantasmas, a seus sonhos, a seus medos: uma ideologia e uma psicanálise do fait divers são possíveis: mas trata-se aí de um mundo cujo conhecimento é apenas intelectual, analítico, elaborado em segundo grau por aquele que fala do fait divers, não por aquele que o consome; no nível da leitura, tudo é dado num fait divers; suas circunstâncias, suas causas, seu passado, seu desenlace; sem duração e sem contexto ele constitui um ser imediato, total, que não remete, pelo menos formalmente, a nada de implícito: é nisso que ele se aparenta com a novela e o conto, e não mais com o romance. É sua imanência que define o fait divers. (BARTHES, 1966, p. 189)'.

Do ponto de vista da apresentação diagramática, o fait divers é uma contraposição às rubricas estereotipadas de um jornal (Economia, Cultura, Política, Esportes, Obituário etc.): tudo aquilo que não cabe nelas, mas que os editores julgam importante publicar, aparece de modo individualizado na estrutura (em um box ou seção destacada), como um acontecimento (normalmente extraordinário) à parte: o bebê de duas cabeças; o jacaré que vive no esgoto; o sumiço das cuecas do time de futebol da terceira divisão. Por outro lado, considerado do ponto de vista da relação crítica e narrativa, o fait divers é um tipo de informação fechada, que se define pela totalidade, pela completude e pela imanência.

Uma mulher de 42 anos foi agredida e mantida em cárcere privado por seu marido, em Franca (400 km de São Paulo), sob a justificativa de que ela o traía "em pensamento". A vítima, segundo depoimento registrado em boletim de ocorrência, foi agredida entre a noite de segunda-feira e a madrugada de terça-feira e ficou presa em seu apartamento, no bairro Vicente Leporace, pelo marido. O acusado, um servente de pedreiro de 38 anos, que foi localizado pela polícia logo após receber denúncias de vizinhos do casal, foi preso por suspeita de lesão corporal (lei Maria da Penha) e cárcere privado. Ele chegou a ser encaminhado para a cadeia do Jardim Guanabara, mas foi transferido para o CDP (Centro de Detenção Provisória) de Franca. Em depoimento à polícia, segundo o delegado Clóves Rodrigues da Costa, ele disse que agrediu a mulher porque ela o traía "por telepatia" e que "pensava em vários homens". A mulher apresentou hematomas pelo corpo e disse ter levado pauladas. "A agressão então deveria ser mental também", disse o delegado. (TIENGO, 2010)

Eis um exemplo clássico. Inicialmente, claro, existe aqui a legitimação dada pela estrutura jornalística. Tudo o que for dito e pensado a respeito deste fait divers passa por esse dispositivo de legitimação - um dispositivo tão automático e natural que mal percebemos sua existência: cremo-lo

\footnotetext{
${ }^{1}$ Para um estudo mais aprofundado da terminologia e o contexto semântico, ver AUCLAIR (1970).
} 
verdadeiro porque está escrito na Folha de S.Paulo. O fait divers opera em uma clara metafísica da credibilidade $^{2}$. Se considerarmos a notícia a partir de suas características formais, podemos ver que a história nos é dada, como diria Barthes, seguindo a diretriz mais clássica de um fait divers: a da imanência - quer dizer, neste caso, uma característica crucial que se revela na sua absoluta completude. Quando terminamos o parágrafo, entendemos que ele está não somente terminado no espaço da página (ou, mais exatamente, no espaço do box) como inteiro em sua própria limitação: ele se constitui como um micromundo. Os acontecimentos que constituem sua origem tiveram, provavelmente, precedentes narrativos importantes, e os acontecimentos de que temos efetivo conhecimento a partir dele devem ter tido suas inevitáveis consequências e continuações: pouco importa, a história (tal como nos é apresentada) já é, em si, uma história total. Nosso fait divers é um evento recortado e recontado de dentro de um evento maior: mas o fait divers que lemos é apenas seu atestado público, e nada mais. Todas as informações processuais (o que exatamente está "descrito no boletim de ocorrência", por exemplo?), passadas no silêncio e no mistério, não existem para nós: e, não obstante, eis sua especificidade, damo-nos já, e plenamente, por satisfeitos ${ }^{3}$.

Essa plasticidade finita e completa (unidade que, em última análise, não deixaria de ser um dispositivo dramático aristotélico, na radical atomização e entrega do espaço e do tempo narrativos), é importante para constituir sua dimensão diegética. "Uma estrutura fechada": estamos, certamente, no território das formas simples ${ }^{4}$.

Falar em fait divers no Renascimento, mais particularmente no Renascimento francês, que é a questão aqui, supõe, portanto, diversos anacronismos: pois a definição de fait divers depende da estrutura do jornal clássico que passou a vigorar no século XIX ${ }^{5}$ - e o primeiro jornal francês propriamente dito, quer dizer, um veículo de informação periódica, a Gazeta de Renaudot, será publicado depois do Renascimento, apenas em 1631. Mas, evidentemente, a ideia de fait divers não se restringe a uma forma narrativa exclusivamente interna a um jornal, seja ele do século XVII ou do século XXI.

Por exemplo,

\footnotetext{
${ }^{2}$ O que é a Folha de S.Paulo, e por que razão o que está escrito lá é verdadeiro, como essa legitimação ocorre?, e assim por diante, são questões que ultrapassam em muito a discussão circunstancial feita aqui. No entanto, não podemos esquecer que essa legitimidade tem paralelos tanto com estratégias ficcionais como também com um amplo jogo retórico com a psicologia dos leitores.

${ }^{3}$ Dito de outro modo, o fait divers não esgota a história à qual se refere. No nosso caso, não esgota a narrativa dos dispositivos legais e processuais implicados em seu prolongamento: de fato, não sabemos nada do acontecido além do que está dito no parágrafo, nem os nomes, nem os endereços, nem os autos, nem as negociações dos advogados e dos promotores, nem mesmo se o caso já foi julgado, se houve questionamento, se a mulher foi colocada sob algum tipo de custódia policial, se o marido foi absolvido ou condenado, nem as penas comutadas. Nada disso, porém, é necessário à completude formal do fait divers nem à sua intelecção narrativa.

${ }^{4}$ No sentido das estudadas por JOLLES (1976) - muito embora não haja, efetivamente, uma forma que possa ser atribuída diretamente ao universo dos faits divers.

${ }^{5}$ O Robert de la Langue Française aponta a data de 1838 como origem do termo fait divers.
} 
No ano de 1515, sexta-feira, vinte e dois de junho, foi decapitado, em Paris, um homem que matou sua mulher enquanto era noivo de outra, perto de Amiens. Levou a tal mulher ao bosque de Senac, perto de Paris, lugar onde a estrangulou com sua cinta, após ter ficado em sua companhia. E querendo desposar aquela com a qual tinha noivado, foi acusado e finalmente decapitado, como eu disse. (LALANNE, 1854, p. 1415)

O interesse pelo fait divers pode, evidentemente, cruzar os séculos das crônicas e das memórias. No entanto, mais precisamente ainda, o que chamo de fait divers no Renascimento europeu faz referência a um certo tipo de conteúdo que aparece em um tipo de particular de impresso. Em espanhol, o pliego ou as relaciones de suceso; em alemão, o Flugschrift, em francês, o canard. E é mais propriamente do cenário francês que me ocuparei aqui.

Pouco antes do aparecimento dos primitivos jornais (estruturas montadas para a transmissão impressa e periódica de notícias, com corpo relativamente organizado e recorrente de articulistas e colaboradores ${ }^{6}$ ), o cenário do circuito noticioso europeu foi invadido por uma grande massa de textos, de caráter pontual, tratando de eventos particulares. Esses textos são parte de um conjunto-universo novo, o dos hoje denominados boletins de informação, ou ocasionais ${ }^{7}$. Embora não fossem os únicos veículos de comunicação no período imediatamente anterior ao aparecimento dos jornais (os mensageiros, os viajantes, soldados em campanha, os éditos e diversos outros dispositivos escritos e orais, como os rumores, cumpriam esta tarefa ${ }^{8}$ ), a difusão de notícias teve, nos boletins publicados pontualmente - isto é, cada vez que um fato importante ou sensacional vinha à luz, daí o nome de "ocasional" -, um dos seus principais meios propagadores. De caráter aristocrático, eles foram um medium importante de circulação de notícias para o grande público já no século XV: incluindo-se aí desde o iletrado - que ouvia os relatos lidos em voz alta pelos alfabetizados - até o cronista e o historiador seus contemporâneos, que utilizavam esses boletins como fontes diretas ou indiretas.

\footnotetext{
${ }^{6} \mathrm{Na}$ França, a imprensa periódica só aparecerá em 1631, com a publicação do primeiro número do semanário La Gaz̧ette, impresso por Théophraste Renaudot. Minha definição do jornal do século XVII não difere muito daquela do jornal tal como a conhecemos hoje - exceto, talvez, neste caso, pelo papel dado à publicidade -, mas, como se trata apenas de uma definição contextual, não entrarei no mérito de sua especificidade.

${ }^{7}$ Uma arqueologia exaustiva da pré-história dos jornais deveria retroagir até contemplar uma análise dos Acta diurna do Império Romano - publicações diárias [diurna] que circulavam trazendo todo tipo de informação (de casamentos a crônicas esportivas e teatrais), redigidas pelos diumarii [diaristas] (ancestrais dos jornalistas modernos). Salústio, por sua vez, um dos protegidos de Júlio César, era o redator de uma publicação periódica, o Commentarius Rerum Novarum [Crônica das coisas novas], semanário que empregava 300 escravos escribas com 10 mil exemplares por edição (Cf. WOLGENSINGER, 1989, p. 14-15).

8 "De façon générale, le rôle fondamental que joue la rumeur dans l'espace public reste à découvrir, alors qu'elle agit à la fois comme information et comme contestation de l'information dans les milieux populaires." (BILLORE \& SORIA, 2011, p. 27).
} 
Trechos de cartas, relatórios, testemunhos em primeira mão (de atores ou observadores diretos, de coadjuvantes), mas também testemunhos indiretos, (retomados de outras fontes, mais ou menos confiáveis) passaram a circular nas prensas dos florescentes e ativos impressores do Renascimento?.

É sabido também que essa voga dos ocasionais na França foi sincrônica a um significativo incremento na velocidade e na amplitude da circulação de notícias: o que se passava na Itália demorava algumas semanas para ser conhecido em Paris, um acontecimento relevante no que então era considerado solo francês demorava em torno de uma semana para ser impresso e difundido nos grandes centros regionais por volta de meados do século $\mathrm{XVI}^{10}$. Essa intensificação do circuito noticioso foi sincrônica também à melhoria dos correios $^{11}$ - o que, por sua vez, foi uma das pré-condições de periodização dos bulletins, desembocando nos semanários do início do século XVII: o jornal é uma equação feliz entre a invenção da imprensa (quer dizer, da prensa de tipos móveis de Gutenberg), do mercado de papel (desenvolvido e disseminado para alimentar as prensas $^{12}$ ) e dos correios. Bem como, claro, de um público consumidor regular ${ }^{13}$.

Se a folha impressa dos ocasionais não substituiu a circulação de manuscritos dos cronistas (anônimos ou não), que continuaram copiados e recopiados no mesmo sistema, algumas particularidades

\footnotetext{
${ }^{9} \mathrm{Na}$ França, a voga começou com as Guerras da Itália: "Sous Charles VIII, de nombreuses pièces de cette nature avaient fait connaître, parfois presque jour après jour, à un public assoiffé de nouvelles, les péripéties des campagnes d'Italie. D'autres reproduisaient les textes de traités importants ou relataient les circonstances d'entrées de souverains ; d'autres, enfin, vulgarisaient le texte de la lettre de Christophe Colomb ou racontaient de passionnants faits divers. Au début du XVIe siècle, les bulletins d'information se font de plus en plus nombreux, et leur clientèle s'accroît. Les règles du genre, dans le choix de nouvelles et dans leur présentation, s'élaborent telles qu'on les retrouvera pratiquées par les éditeurs de gazettes, par les canardiers et par les journalistes à venir.” (SEGUIN, 1961, p. 7).

10 "Il semble que les Parisiens, les Rouennais, les Lyonnais pouvaient lire le récit d'un événement quelques jours seulement après qu'il ait lieu en France ; ils n'attendaient guère plus de deux à trois semaines pour connaitre ceux d'Italie ou d'Egypte. Pour publier ces bulletins, il suffit de quelques jours au cours de la première moitié du XVIe siècle pour les événements survenus dans le royaume, deux à trois semaines pour les nouvelles de l'étranger. A la fin du XVIe siècle, d'après le journal de Pierre de L'Estoile, il faut une semaine pour savoir ce qui se passe dans les Pays-Bas, douze jours pour le monde méditerranéen. En 1622 encore, les privilèges [licença de impressão] portent des dates postérieures de deux, six et même dix jours au déroulement des faits français, quinze jours pour les pays voisins." (BELLANGER, 1969, p. 33).

11 O correio francês foi oficialmente criado por Luís XI em 1462. O sistema postal foi assim chamado "porque envolvia o estabelecimento de postos com homens e cavalos estacionados ao longo de algumas estradas ou rotas de correio". Sistemas estruturados de informação foram vitais não apenas na transmissão de notícias, mas também no estabelecimento dos grandes Estados europeus do Renascimento. É notório que, antes dos correios e de rotas que assegurassem a boa circulação de dados, os grandes aristocratas e, sobretudo, os reis, precisavam se deslocar bastante para manter seus domínios sob controle. Carlos V (reinando entre 1520 e 1556) é um exemplo, com 40 viagens: "dez à Holanda, nove à Alemanha, sete à Itália, seis à Espanha, quatro à França, duas à Inglaterra e duas ao norte da África”. Já durante o reinado de seu sucessor, Felipe II (1556-1598), a ubiquidade do rei é sensivelmente menor: "Ele preferia, na medida do possível, permanecer em um lugar, Madri ou seus arredores, e sentar a sua mesa de trabalho durante várias horas por dia, lendo e anotando os documentos que chegavam de todos os seus domínios. Não é de estranhar que os súditos tenham-no apelidado de 'el Rey papelero"” (BRIGGS \& BURKE, 2016, p. 33 e p. 34).
}

12 Ver VERNUS, 2004.

13 A ideia de semanário não existe por acaso. É função direta da periodicidade dos correios, que servia as cidades a cada sete dias: "Au début du XVIIe siècle, la régularité des services postaux - le courrier, en principe, partait des grandes villes une fois par semaine - assura la régularité de la réception des informations et permit la régularité de la réception des feuilles de nouvelles. (...) Elle fut hebdomadaire comme l'arrivée et le départ des courriers." (MANEVY, 1958, p. 10). 
foram sendo sentidas na dinâmica da informação impressa. Os boletins, que, de início, tal como no caso das crônicas e das memórias clássicas e medievais, se concentraram sobre acontecimentos bastante aristocráticos (entronizações, casamentos reais, grandes batalhas, golpes de estado ${ }^{14}$ ), vão, aos poucos, oferecendo um quadro mais amplo, levando ao seu público também notícias sobre a atualidade geral quer dizer, notícias cujo fundo e interesse não era necessariamente aristocrático. Essa mudança de conteúdo dos ocasionais políticos e históricos do século XV para os do século XVI, de espectro mais largo, é de fundamental importância para todo o circuito de narrativas produzidas no século XVI - e não somente no que diz respeito às gazetas e periódicos posteriores. E tal como no caso do livro, mas ampliado aqui por conta das vicissitudes do formato, a facilidade de imprimir cópias a partir de uma matriz (inerente ao sistema de prensa de tipos móveis de Gutenberg) lhe forneceu, portanto, um meio de produção eficiente, massivo e relativamente barato $^{15}$.

A partir do começo do início do século XVI, na continuidade desse mercado, os boletins franceses começaram a mostrar também um interesse sistemático pelo acontecimento puramente quotidiano, i.e., o acontecimento sem necessariamente uma implicação política, econômica ou religiosa clara ou ao menos declarada. Em outras palavras, por esta época, os editores também começaram a publicar aquilo que modernamente chamamos de fait divers ${ }^{16}$.

Essa mudança de atitude com relação aos "fatos" da "vida ordinária" (ainda que pautada pelo extraordinário) é uma verdadeira revolução na história da informação. De temática ampla, indo de catástrofes naturais a prodígios, de processos de bruxaria a assassinatos, o canard é evidentemente um veículo novo, que veio estabelecer um universo diferente, ainda que solidário, daquele dos boletins de informação anteriores.

Dos 517 canards repertoriados e estudados por Jean-Pierre Seguin (na obra que até hoje se apresenta como o principal inventário desse material) ${ }^{17}$, numa amostragem que vai de 1529 a 1631 (ou

\footnotetext{
${ }^{14}$ Exceção feita aos boletins do final do século XV, sobretudo na Itália e nos Países Baixos, que também traficavam informações de caráter funcional para o comércio.

${ }^{15}$ Para os impressores do Renascimento, o valor econômico dos boletins de informação é, desde o início, bastante significativo, mas de modo pontual: "S’il existe déjà quelques spécialistes [em imprimir ocasionais] - P. le Carron et J. Lhomme surtout ont droit à ce titre - pour la plupart des autres imprimeurs, les bulletins d'information n'étaient qu'un moyen, plus ou moins souvent employé, de réaliser une bonne affaire en vendant rapidement, à une clientèle étendue, une marchandise produite à peu frais." (SEGUIN, 1961, p. 50).

16 "Pour la période 1488 à 1529, J.-P. Seguin a retrouvé près de 200 occasionnels, mais aucun ne relate un fait divers, ce qui est assez curieux. A partir de cette date, les canards se multiplient. Le Journal d'un bourgeois de Paris [sous le règne de François I], de 1515 à 1536, en consigne d'innombrables. Pierre Boaistuau en rassemble dans un recueil sous le titre Histoires prodigieuses en 1560.” (BELLANGER, 1969, p. 41). Mas esse estado de coisas foi profundamente revisto nos últimos anos, e em minha pesquisa recuei o período do interesse e publicação impressa dos faits divers em língua francesa em pelo menos trinta anos, começando por volta de 1500.
}

${ }^{17}$ SEGUIN, 1964. 
seja, um século de produção), 109 são relatos de crimes; 116 de calamidades diversas (enchentes, tempestades etc.); 95 de fenômenos celestes; e 180 descrevem eventos mais ou menos maravilhosos ${ }^{18}$. Contada dessa maneira, essa pequena história permite considerar várias questões, mas talvez a mais importante seja a perspectiva desse material (essencialmente popular) com a cultura letrada sua contemporânea. Podemos pensar no caso particular dos canards de cunho prodigioso. Não é muito difícil entender essa relação. De um modo geral, podemos dividir o universo dos textos do século XVI especializados em eventos prodigiosos/teratológicos (monstros, fenômenos bizarros etc.) entre compilações históricas eruditas ${ }^{19}$; textos científicos ou com claras preocupações epistemológicas e taxonômicas ${ }^{20}$; e, finalmente, material de amplo consumo, tais como os canards. Devemos acrescentar aí, talvez, trechos dos diários contemporâneos (como o journal de Pierre de L'Estoile).

Neste contexto, as compilações eruditas e os textos de caráter epistemológico são geralmente históricos e/ou indiretos, isto é, coletâneas que não se pretendem categoricamente testemunhas oculares dos fatos narrados: é uma consequência direta do seu sistema de legitimação, apoiado exclusivamente na autoridade citacional dos autores antigos. Já os canards, pela própria natureza de representação informacional do fait divers, frequentemente invocam sua condição imediata de testemunho ou de proximidade espaçotemporal com o objeto narrado: mesmo se essa qualidade testemunhal não possa, na maioria das vezes, ser provada, ou seja, comprovadamente falsa, ela permanece como marca da sua esfera de ação narrativa - que, em certo sentido, chamaríamos hoje de "jornalística". Todos os autores eruditos, em algum momento, flertaram com os canards que narram prodígios - estes, por sua vez, constituem o elemento “popular” (ou não necessariamente "científico") nesta divisão essencialmente erudita.

A leitura comparativa de tais textos nos mostra que as fronteiras entre as considerações de ordem erudita (tratados científicos ou quase) acerca dos acontecimentos prodigiosos e monstruosos e as considerações similares de caráter popular (expressão documental que os canards de teratológicos eles mesmos representam), permaneceram diáfanas por décadas. As Histoires prodigieuses (1560), de Pierre de Boiastuau, por exemplo, embora escritas para um público erudito, caíram no gosto dos colporteurs e seu público, encontrando terreno propício para cópias e disseminações, possibilitando aos canards de prodígio e aos textos populares da Biblioteca Blene (coleções de títulos populares do início do século XVII, almanaques e similares) numa contramaré, canibalizarem tratados eruditos e reproduzirem textos tirados

\footnotetext{
${ }^{18}$ Essa divisão nem sempre fica clara na leitura dos textos, pois não quer dizer que temas diferentes não possam se interpenetrar num mesmo canard. Vale lembrar, também, que as entradas do repertório de SEGUIN (1964) incluem duplicatas e referências a outros suportes (como os diários), o que praticamente duplica o número total de seus faits divers.

${ }^{19}$ De Prodigiis libri III, de Polidoro Virgílio; o De Ostentis, de Camerarius, o Velho; as Histoires prodigieuses de Pierre de Boaistuau e seguidores.

${ }^{20}$ Como Des monstres et prodiges do médico francês Ambroise Paré [1510-1590] e o Tractatus de monstris (1570) de Arnaud Sorbin (1532-1606), posteriormente incorporado à coletânea de Histoires prodigieuses.
} 
dos continuadores de Boaistuau como se fossem textos originais ${ }^{21}$ : o canard prodigioso se mostrando, assim, extremamente ágil e suscetível às interpolações e aos empréstimos diante do material feito para o público letrado $^{22}$. No universo geral das narrativas de prodígio, vê-se que os interesses dos diferentes autores (canardiers, memorialistas e teóricos), e de seus respectivos leitores, são mais do que simplesmente convergentes. Efetivamente, há claros indícios de uma simbiose entre o material "erudito" e o "popular": Ambroise Paré não apenas leu como efetivamente fez uso dos canards como fontes diretas em seu Des Monstres et prodiges (1573), um dos mais importantes estudos teratológicos do século XVI - dando aos canards de prodígio, indiretamente, certa forma de legitimação "científica"23.

Essa relação de simbiose acontecerá até pelo menos o começo do século XVII, quando os textos eruditos sobre prodígios se estabilizarem em um modelo (auto)referencial próprio e consistente trazendo, por consequência, o necessário desprezo pela literatura ambulante dos canards. É um desprezo que traduz uma mutação geral: as Observationum medicarum, de Johann Schenck (1596), em princípio outra enorme compilação histórica de anomalias e monstruosidades, já indica a seus leitores que o estudo da monstruosidade humana é uma atribuição exclusiva da medicina (logo, dos profissionais treinados pela universidade), posição tomada paulatinamente por outros compiladores ${ }^{24}$. Em 1560, Boaistuau inaugurara um gênero de texto prodigioso tão próximo do canard (alguns dos causos descritos em sua obra foram emprestados diretamente ao material de colportage) que, em sentido contrário, permitiu aos canards canibalizarem sua nomenclatura (“bistoire prodigieuse”) nos seus próprios títulos, constituindo uma marca quase técnica ${ }^{25}$. Mas trinta anos depois, a edição de 1598 (a última) das Histoires prodigieuses marca a

21 “(...) l'Almanach pour l'an de Grâce 1679 s'intéresse aux «femmes qui ont enfanté grand nombre d'enfants » et recopie tranquillement le chapitre VII [das Histoires progidieuses] de Claude Tisserant.” (CEARD, 1996, p. 471).

22 “Entre cette littérature populaire [os canards] et la littérature savante, les recueils d'bistoires prodigieuses constituent un intermédiaire qui assure une continuité de l'une à l'autre et qui, de fait, sert souvent de relais; Boaistuau a recueilli dans les canards beaucoup de faits qu'à son tour Paré lui emprunte. Il arrive même que l'on se demande si certains canards n'ont pas eu pour auteur l'auteur d'un recueil d'histoires prodigieuses [um canard de 1578 editado por Jean de Lastre aparece integralmente no cap. 5 das Histoires prodigieuses de Rod. Hoyer]." (CEARD, 1996, p. 470).

23 'Le public savant et ce public plus populaire n'étaient certes pas, à l'origine, absolument étrangers l'un à l'autre. De même, les deux littératures, populaire et savante, ne s’ignoraient pas. Au temps où Paré compose son livre Des monstres et prodiges, il n’hésite pas à emprunter des récits aux canards, qu'il connait souvent directement [veja-se Des Monstres et prodiges...., fim do cap. XIX].” (CEARD, 1996, p. 470).

24 "A mesure que la littérature savante, grâce aux travaux de Schenck et à d'autres compilations du même genre [Riolan, nos Discours des Hermaphrodits, 1614, aconselha o leitor a ler os livros de Schenck], disposera de ses propres sources d'information, elle marquera plus de mépris pour les canards : la traduction [francesa] du livre de [Fortunio] Liceti, [De monstrorum natura, caussis, et differentiis libri duo, 1616], qui paraît en 1708, est suivie d'un très grand nombre d'observations rassemblées par Gérard Blasius [Gerhardt Blaes] et qui sont tirées, prévient-on le lecteur, 'non pas de ce que nous apprennent ces feuilles volantes, qu'on publie tous les jours dans nos Ruës: mais des ouvrages des plus celebres Medecins'.” (CEARD, 1996, p. 470).

${ }^{25}$ Embora não fosse inicialmente de uso exclusivo dos canards descrevendo prodígios - pois canards criminais também a utilizaram - a expressão Histoire prodigieuse... passou, na primeira metade do século XVII, a descrever majoritariamente casos específicos desse gênero: Histoire prodigieuse de sept épouvantables monstres sortis des abîmes de la terre représentés par des signes étranges et abominables devant Dieu,... Paris : J. Chemin, 1618; Histoire prodigieuse d'un ours monstrueusement grand \& espouvantable, tuant \& devorant tout ce qu'il treuvoit devant luy, \& violant femmes \& filles au pays de Forests : qui fut tué par le Capitaine la Halle de Sainct Estienne de Furant au bois de la Trappe pres Sainct Geny de Mallefaut. Lyon, Claude Chastellard, 1613; Histoire prodigieuse et admirable arrivée en Normandie 
passagem definitiva da obra para as mãos dos camelôs, seu alijamento do debate técnico erudito e, consequentemente, seu progressivo esquecimento posterior.

O caso dos canards teratológicos é importante porque, neles, o tema não se reduz apenas a uma epifania aristotélica do erro, definida tecnicamente, grosso modo, pela ruptura da cadeia normativa dos $\operatorname{seres}^{26}$. A permanência e a pervasividade do tema leva a um lugar verdadeiramente interdisciplinar, perpassado por diversas instâncias ao mesmo tempo complementares e centrífugas: nos monstros veiculados por esses folhetins está implicada uma filosofia da natureza, que carrega consigo um modelo de ordem do qual a própria teratologia folhetinesca, de cunho apocalíptico e sensacionalista, parece ser a força disruptiva. Neles vemos o diálogo com o universo médico-anatômico moderno (o De Humani Corporis Fabrica de Vesalius é de 1543), ocupado em coletar as diferenças formais para definir a unidade da espécie humana; neles vemos uma reapropriação e uma ressignificação da topografia europeia (ao mesmo tempo em que as Grandes Navegações aumentavam a escala do mundo conhecido e produziam relatos monstruosos em terras distantes, os canards intensificavam a produção de monstros e prodígios intraeuropeus); neles vemos símbolos de desordem no corpo político, uma força apologética e apocalíptica, de propaganda religiosa, implicada nas disputas entre católicos e protestantes - como na apropriação midiática do Papstesel (o Papa-Asno) de Lutero e Melanchton, o famoso Flugschrift publicado em 1523, com xilogravura de Lucas Cranach, no alvorecer da Reforma (mas que, na verdade, retoma um relato teratológico italiano de 1496).

O que a história imbricada desses documentos “eruditos" e "populares" nos mostra, portanto, é um momento extremamente importante na história cultural europeia, e que pode ser ampliado para outros tipos de documentos e saberes: o de um entrecruzamento de epistemologias similares que estão em vias de se separarem definitivamente - mas ainda não o fizeram. O que guiará essa separação mais adiante não é somente algo de ordem técnica e científica - constituída a partir de reificações algo fantasiosas da "objetividade científica", um truísmo positivista pouco adequado ao comportamento dos cientistas da época pré-moderna ${ }^{27}$. Não é uma separação epistemológica entre um saber popular (cientificamente impreciso e por isso já condenado ao fracasso) e um saber erudito (cientificamente alicerçado em suas próprias bases metodológicas e materiais). É antes de uma separação de ordem cultural. E aqui, por volta de meados do século XVI, entre os que se debruçaram sobre o monstruoso, a

\footnotetext{
et pays du Maine, du ravage qu'y ont fait une quantité d'oiseaux étrangers et inconnus, sur les fruits et arbres desdits pays... Paris : I. Mesnier, 1618; entre outros.

26 “Com efeito, o monstro pertence às categorias de fenômenos contrários à natureza, à natureza considerada não na sua constância absoluta, mas no seu curso ordinário: pois do ponto de vista da natureza eterna e submetida à necessidade, nada se produz contra a natureza. Enquanto que se dá o inverso nos fenômenos que, na generalidade dos casos [i.e., na maior parte das vezes], são de um modo, mas podem também ser de outro modo.” (ARISTOTE, 1961, p. 154-155). Essa concepção do monstruoso é também a de Ambroise Paré.
}

${ }^{27}$ DASTON \& GALISON, 2007, p. 17 e ss. 
superioridade de uma presunção de posicionamento "etnográfico", separando soberanamente um saber "erudito" (teratologias científicas) e um saber "popular" (não técnico, visto no máximo como mera curiosidade, mostrado pelos canards), ainda não produziu um tipo de especialista independente, puro, com um saber específico com fontes e debates perfeitamente delimitados por uma "comunidade" de connoisseurs que se entendem enquanto tal: no caso dos monstros, um teratologista "retirado" de um saber local e comum $^{28}$.

Neste domínio, seu conhecimento erudito ainda não é autorreferente, e os autores eruditos não veem como problemática a leitura e o uso de textos anônimos, cujo saber não é referendado por seus pares ou por qualquer grande autor conhecido. Aqui o "vulgaire ignorant” ainda não saiu de cena (através de uma dissimulada aplicação de um dispositivo cortesão junto à ciência), e, neste campo, o sábio ainda não corrige os erros do vulgo - este "vulgar", ou ao menos sua idealização, campônio ou citadino, que poderia, nos estertores, fornecer até mesmo a própria base material de um ou vários saberes ${ }^{29}$.

Ao observarmos outros textos populares (como por exemplo os almanaques astrológicos dos séculos XVI-XVII) à luz de todas as remodelagens científicas e filosóficas instauradas a partir do Cinquecento, o que vemos neles, curiosamente, é um fenômeno de estabilidade. Enquanto o aristotelismo medieval é posto de cabeça para baixo pela ciência renascentista, o universo e a visão de mundo dos leitores de canards seus contemporâneos (aristotélica, em larga medida) permanece estruturalmente impassível: nenhum dos novos questionamentos e posições a respeito do cosmo e do mundo ao redor surte aí efeito algum. Evidentemente, a amostragem mental desse público "popular", ainda que estável, é difícil de discernir de forma clara. A continuidade de consumo dos mesmos impressos (como os almanaques, publicados sem qualquer mudança durante décadas a fio) dão dele, porém, uma medida bastante sugestiva (ainda que indireta): diferente do que acontece quando observamos os debates eruditos, o público em geral parece não se mover nem se deixar afetar por nenhuma das reviravoltas epistemológicas de sua época. É neste sentido que o estudo desse material ajuda a entender a problemática das concepções de mundo, cosmo, indivíduo, religião etc. no Renascimento de um modo diferente da abordagem através dos textos canônicos. É na regularidade editorial desses textos “populares”, através

\footnotetext{
${ }^{28} \mathrm{Na}$ expressão de Peter Burke: "Em 1500, a cultura popular era uma cultura de todos: uma segunda cultura para os instruídos e a única cultura para todos os outros. Em 1800, porém, na maior parte da Europa, o clero, a nobreza, os comerciantes, os profissionais liberais - e suas mulheres - haviam abandonado a cultura popular às classes baixas, das quais agora estavam mais do que nunca separados por profundas diferenças de concepção de mundo. Um sintoma dessa retirada é a modificação do sentido da palavra 'povo', usada com menor frequência do que antes para designar 'todo mundo' ou 'gente respeitável', e com maior frequência para designar 'gente simples'. (...) Essa separação entre a cultura de classe alta e a cultura de classe baixa pode ser vista com extrema clareza naquelas partes da Europa onde a imitação da corte significou que as classes superiores locais adotaram uma língua literalmente diferente da do povo. (...) Não foi apenas a língua das pessoas comuns que foi rejeitada pelas classes superiores, e sim toda a sua cultura.” (BURKE, 2010, p. 356 e p. 358).

${ }^{29}$ Como é evidente, por exemplo, no caso dos Calendriers des bergers, almanaques prospectivos que começaram a ser produzidos na década de 1490 (ainda como incunábulos). De início puramente astrológicos, já na segunda edição passam a conter também informações de ordem medicinal (anatomias), teológica (tábuas de pecados), zoológica (poemas descrevendo pássaros) etc.
} 
dos decênios e dos séculos e em seus pressupostos, que podemos traçar uma ideia do que pensavam os indivíduos ordinários dessa época. E, a partir daqui, aqueles textos canônicos que compõem a tradição filosófica ocidental se iluminam de forma inesperada.

Sendo assim, os faits divers e seu contexto editorial ajudam a entender de que modo a auctoritas prémoderna, sempre pautada no respeito aos clássicos greco-romanos, se hierarquiza de maneira totalmente diversa do modelo "medieval" da cultura. Neste último, fronteiras rígidas entre as diversas disciplinas e formas de conhecimento foram impostas, em geral, pela estrutura das universidades e pelo formalismo teológico-filosófico - fronteiras que, quase biunivocamente, se referiam ao contexto sócio-político dos discursos e formas de viver do mundo feudal. Nessa hierarquia dos saberes reinava a Teologia, seguida pela metafísica, pelas matemáticas e ciências naturais (o trivium e o quadrivium), relegando as diferentes formas de arte (artes manuais) para o exterior das disciplinas científicas - sem realmente diferenciar as artes (que chamaríamos hoje de belas artes ou artes plásticas) dos ofícios e do artesanato em geral. É no esfacelamento dessa ordenação que reside um dos aspectos mais característicos do movimento cultural renascentista: a horizontalização dos saberes, aquilo que PANOFSKY (1962) denominou a “descompartimentação" renascentista, quer dizer, a comunicação latitudinal dos campos teóricos e práticos do conhecimento, assegurando a equivalência e a interpenetração das áreas técnicas, artísticas e científicas. Mantendo-se sob os olhos os mesmos fenômenos culturais, agora no decorrer do final do Renascimento, vê-se claramente que as simbioses entre as publicações eruditas e os faits divers também criaram aspectos verticais, mas totalmente diferentes, nos quais a auctoritas doravante se impõe na relação criada entre o douto e o ignorante, entre o letrado e o iletrado, entre a corte e o povo - o "povo", quer dizer, toda uma "episteme popular" que, durante certo momento, até meados do século XVI, será chamada a compor o cenário epistemológico da ciência natural de sua época; mas, logo depois, será mantida sob controle, expulsa das valorizações e conquistas das novas ciências experimentais ${ }^{30}$.

\footnotetext{
${ }^{30}$ Laurent Joubert, um dos médicos de Henrique de Navarra, publicará em 1578, junto a Simon Millanges (primeiro editor dos Ensaios de Montaigne), a primeira edição dos Erros populares da Medicina, obra que se tornou clássica no que dizia respeito ao seu ofício, já anunciando essa mudança. Para Joubert, a existência do erro humano só se justifica se pensamos o homem não numa ontologia que valoriza a descoberta sempre inata da verdade (segundo ele, uma doutrina de fundo platônico), mas sim na paulatina e consciente acumulação do saber, que poderá ser bom ou ruim dependendo da qualidade do ensino e dos mestres (logo, ainda segundo ele, uma doutrina de fundo aristotélico). Sendo assim, a finalidade pedagógica de seu tratado é imbuída de forte sabor paternalista, onde o "vulgaire ignorant" precisa ser posto "en un meilleur chemin": pois o ignorante "ne le fait malicieusement, ou en intention de nuire", sendo "le devoir des Medecins de luy dissuader ces fausses opinions \& procedure, \& l'instruire de faire mieux ce que luy concerne”. Prefácio a Marguerite de Navarra in Laurent JOUBERT, Erreurs populaires au fait de la Medecine et regime de santé corrigés par M. Laur. Joubert. Bordeaux, Simon Millanges, 1578. Note-se que a palavra "corrigés" faz parte do título na folha de rosto.
} 


\section{REFERÊNCIAS}

ARISTOTE. De la génération des animaux. Texte établi et traduit par Pierre Louys. Paris: Les Belles Lettres, 1961.

AUCLAIR, Georges. Le mana quotidien: structures et fonctions de la chronique des faits divers. Paris: Anthropos, 1970.

BARTHES, Roland. "Structure du fait divers". In: Essais critiques. Paris: Seuil, 1966.

BELLANGER, Claude (ed.), Histoire générale de la presse française, Vol. 1. Paris: PUF, 1969.

BILLORÉ, Maïté \& SORIA, Myriam. La Rumeur au Moyen Age. Rennes: Presses Universitaires de Rennes, 2011.

BRIGGS, Asa \& BURKE, Peter. Uma História Social da Mídia. Rio de Janeiro: Zahar, 2016.

BURKE, Peter. Cultura Popular na Idade Moderna. São Paulo: Cia das Letras, 2010.

CEARD, Jean. La Nature et les prodiges. Genève: Droz, 1996.

DASTON, Lorraine \& GALISON, Peter. Objectivity. New York: Zone Books, 2007.

JOLLES, Andre. Formas Simples [Einfache Formen, 1930]. Cultrix, 1976.

LALANNE, Ludovic (ed.). Journal d'un bourgeois de Paris sous le regne de François I. Paris: Renouard, 1854.

MANEVY, Raymond. La presse française de Renaudot à Rochefort. Paris: J. Foret, 1958.

PANOFSKY, Erwin. "Artist, scientist, genius: notes on the Renaissance-Dammerung". In:

FERGUSON, Wallace (ed.). The Renaissance. Six essays. New York: Harper Torchbooks, 1962, p. 129-131.

SEGUIN, Jean-Pierre. L'Information en France de Louis XII a Henri II. Genève: Droz, 1961.

SEGUIN, Jean-Pierre. L'Information en France avant le périodique. Paris: Maisonneuve et Larose, 1964.

TIENGO, Rodolfo. "Mulher é espancada em Franca (SP) sob acusação de trair marido em pensamento" in Folha de S.Paulo, Caderno Cotidiano, 14/10/2010 (edição eletrônica). Disponível em:<http://www1.folha.uol.com.br/cotidiano/814719-mulher-e-espancada-em-franca-sp-sobacusacao-de-trair-marido-em-pensamento.shtml>. Acesso em: 10/12/2019.

VERNUS, Michel. La fabuleuse histoire du papier. Cabédita Editions, 2004.

WOLGENSINGER, Jacques. L'Histoire à la Une. La grande aventure de la Presse. Paris: Gallimard, 1989.

Recebido em: 28 de novembro de 2019.

Aprovado em: 15 de dezembro de 2019. 